\title{
ESCOLARIZACT̃̃O FORMAL E DIMENSÕES CURRICULARES PARA ALUNOS COM AUTISMO: O ESTADO DA ARTE DA PRODUÇ̃̃O ACADÊMICA BRASILEIRA
}

\author{
Anderson Jonas das Neves \\ Carolina de Santi Antonelli** \\ Mariana Girotto Carvalho da Silva*** \\ Vera Lúcia Messias Fialho Capellini****
}

RESUMO: A mediação do conhecimento é um dos deveres da educação, independentemente dos atributos físicos e mentais do alunado. Dado que o currículo pode configurar-se como uma barreira pedagógica para a escolarização formal de indivíduos com autismo, este estudo objetivou mapear a produção acadêmica nacional, disponível no Banco de Teses e Dissertações da Coordenação de Aperfeiçoamento de Pessoal do Ensino Superior (BTD-CAPES) sobre o processo de escolarização formal e as dimensões curriculares para alunos com essa característica. Organizou-se um banco de dados com 157 teses e dissertações, as quais foram submetidas à categorização, análise estatística e temática. Os resultados indicam restrita produção acadêmica pelos programas de mestrado e doutorado do país. Conclui-se que há necessidade de pesquisas que amparem e propiciem estratégias pedagógicas para permitir ao aluno com autismo apropriar-se dos conteúdos curriculares da educação formal.

Palavras-chave: Estado da Arte; Educação; Autismo; Currículo.

\footnotetext{
* Mestrando do Programa de Pós-Graduação em Psicologia do Desenvolvimento e Aprendizagem da Universidade Estadual Paulista Júlio de Mesquita Filho (UNESP-Bauru) e membro do Instituto Nacional de Ciência e Tecnologia - Comportamento, Cognição e Ensino (INCT-ECCE);

Email: filosofoajn@gmail.com

* * Mestranda do Programa de Pós-Graduação em Psicologia do Desenvolvimento e Aprendizagem da Universidade Estadual Paulista Júlio de Mesquita Filho (UNESP-Bauru)

Email: carolina_santonelli@yahoo.com.br

*** Mestranda do Programa de Pós-Graduação em Psicologia do Desenvolvimento e Aprendizagem da Universidade Estadual Paulista Júlio de Mesquita Filho (UNESP-Bauru)

Email: marianagirotto@ig.com.br

**** Doutora em Educação Especial Universidade Federal de São Carlos (UFSCAR); Professora do Departamento de Educação e do Programa de Pós-Graduação em Psicologia do Desenvolvimento e Aprendizagem da Universidade Estadual Paulista Júlio de Mesquita Filho (UNESP-Bauru); Membro do Observatório Nacional de Educação Especial.

Email: vlmfcapellini@gmail.com
} 


\section{FORMAL SCHOOLING AND CURRICULAR DIMENSIONS FOR STUDENTS WITH AUTISM: THE STATE OF ART OF BRAZILIAN ACADEMIC PRODUCTION}

ABSTRACT: Knowledge mediation is one of the Education duties, regardless of students' physical and mental attributes. Given that the curriculum can be configured as a pedagogical barrier for formal schooling for individuals with autism, this study aimed to map the national academic production, available on BTD-CAPES, regarding the process of formal schooling and curricular dimensions for students with this characteristic. We organized a database with 157 theses and dissertations, which were submitted to categorization, thematic and statistical analysis. The results indicate limited academic production by master's degree and doctorate program in the country. We concluded that there is need for research that support and encourage pedagogical strategies to enable the student with autism appropriate itself of curricular contents of formal education.

Keywords: State of the art. Education. Autism. Curriculum.

\section{INTRODUÇÃo}

A escola, instituição social configurada como espaço por excelência da educação e da mediação social sujeito-sociedade, detém a função social irrevogável e fundamental de oferecer condições potenciais para que os conhecimentos produzidos historicamente pela humanidade sejam devidamente democratizados, apropriados e objetivados pelos alunos, independentemente de suas condições físicas, intelectuais, socioeconômicas e culturais (CAIADO; LAPLANE, 2009; FONSECA, 2011; TRAVERSINI et al., 2012). Nessa perspectiva, a educação é concebida como um conjunto de recursos, estratégias, metodologias, conteúdos e recursos humanos que, ao estarem organizados e dispostos nas diversas instâncias do universo escolar, devem produzir valores, condutas e processos que visem à valorização e ao respeito à diversidade humana, à apropriação de conhecimentos, à formação cidadã e aos novos olhares e práticas sobre o ensinar e o aprender (LEITE; BORELLI, MARTINS, 2013).

Com fundamento nessa concepção, declara-se uma finalidade clara e única da educação: oferecer as condições necessárias e suficientes para o acesso, a permanência e o êxito acadêmico de todos os alunos, sem distinção, nas múltiplas dimensões (domínio de conhecimentos, socialização, dentre outras competências humanas) que o envolvem (ECHEITA, 2010). 
Para Echeita (2010), Fonseca (2011), Thomazi e Asinelli (2009) e Garcia (2006), garantir o processo de aprendizagem dos conhecimentos produzidos historicamente e construir as habilidades necessárias para o exercício pleno da cidadania do indivíduo são os objetivos primários de toda ação educacional. Dessa forma, faz-se necessário refletir sobre o como, o porquê e o para que/quem os conhecimentos científicos elaborados pela humanidade são oferecidos (e garantidos) pelo atual sistema educacional, bem como de que maneira esses saberes são sistematizados nos currículos do ensino formal.

Do ponto de vista etimológico, a palavra currículo (do latim curriculum) remete à ideia de percurso a ser realizado. Esse termo evoluiu no decorrer do tempo, sendo atualmente definido pelo dicionário Michaelis (2009) como um conjunto de disciplinas de um curso escolar, ou seja, documento que estabelece seleção, sequência, maneira e tempo de apresentação dos conteúdos e as respectivas avaliações da aprendizagem.

A abordagem curricular é objeto de atenção do Ministério da Educação e Cultura (MEC), em cumprimento ao art. 210 da Constituição Federal de 1988 (BRASIL, 1988), que determina como dever do Estado para com a educação estabelecer conteúdos mínimos para o Ensino Fundamental, visando à formação básica comum e respeito aos valores culturais, artísticos, nacionais e regionais. Assim sendo, foram elaborados e distribuídos pelo MEC, a partir de 1995, os Referenciais Curriculares Nacionais para a Educação Infantil (RCNEI), os Parâmetros Curriculares Nacionais (PCN) para o Ensino Fundamental e os Referenciais Curriculares para o Ensino Médio (RCNEM). Somente a posteriori, o Conselho Nacional de Educação definiu as Diretrizes Curriculares para a Educação Básica por meio da Resolução CNE/CEB nº 04/2010 (BRASIL, 2010).

Considerando as disposições instituídas pelos documentos oficiais do MEC, o currículo passa a ser compreendido como um processo integrado que deve ser cuidadosamente sistematizado, levando-se em conta conteúdos científicos previamente definidos, estratégias pedagógicas, as situações de ensino e formas de avaliação da aprendizagem. Portanto, para além de um conjunto de atividades nucleares, o currículo é a própria expressão das intenções da escola (CANDAU, 2002). Muito mais que um projeto de escola, essas intenções refletem ou deveriam refletir um projeto de sociedade (SIQUEIRA; PEREIRA, 1998; FREITAS, 2000; CAPELLINI, 2004; SANTOS, 2007). 
O currículo, na perspectiva da instituição escolar, constituise no documento que norteia todas as ações pedagógicas da escola e tem a responsabilidade planificada de atenção às necessidades educacionais de todos os alunos (THOMAZI; ASINELLI, 2009; GARCIA, 2006; FONSECA, 2011). Desse modo, não deve ser assimilado enquanto um documento imutável; ao contrário, este deve admitir modalidades de ajustes que se justifiquem como necessárias para garantir que os alunos tenham acesso aos objetivos preconizados pelo plano de ensino.

Cabe à escola organizar o currículo e prever modificações, empregando os ajustes curriculares necessários, quer seja nas práticas educativas, nas estratégias de ensino, nos recursos ou mesmo nos procedimentos (PERRENOUD, 2001); desse modo, procura-se garantir que todos os alunos tenham uma aprendizagem significativa dos conteúdos estabelecidos para o ano e/ou para o ciclo escolar (FERREIRA, 2007). Os ajustes curriculares - preconizados com a LDB 9.394/1996 (Lei de Diretrizes e Bases da Educação) e os Parâmetros Curriculares Nacionais de adaptações curriculares (BRASIL, 1999) - têm sido evidenciados na literatura como elementos importantes de acesso e garantia de aprendizagem dos conhecimentos formulados pelo currículo comum (LEITE; MARTINS, 2007; LEITE; MARTINS; PEREIRA, 2007), todavia ainda requerem uma adequada delimitação conceitual das modalidades que os integram (MAJÓN; GIL; GARRIDO, 1997; ZANATA, 2004; LEITE; MARTINS, 2010). Nessa direção, Fonseca (2011) salientou as diferenças nas modalidades dos ajustes curriculares que poderiam (e deveriam) ser aplicadas a alunos com ou sem deficiência (GOMES, 2007), classificando-as em flexibilização, adequação e adaptação, as quais objetivam oferecer condições favoráveis de ensino de determinados conteúdos curriculares, bem como atender às peculiaridades do alunado.

De acordo com Fonseca (2011), a flexibilização consiste na programação das atividades elaboradas para sala de aula e diz respeito às mudanças nas estratégias pedagógicas, sem que sejam necessárias alterações dos conteúdos curriculares previstos. A adequação curricular, por sua vez, compreende atividades individualizadas que permitem o acesso ao currículo (FONSECA,2011), no qual o professor atende, especificamente, às necessidades educacionais de cada aluno, prevendo, assim, adequações no planejamento curricular de ensino, tais como mudanças nos objetivos, conteúdos, recursos e práticas pedagógicas. Assim, o currículo adaptado decorre diretamente das 
ações de flexibilização e adequação curricular (ZANATA, 2004), nas quais a matriz curricular é mantida e são modificadas as condições de ensino, as estratégias pedagógicas, os materiais didáticos, os recursos de ensino, a forma de apresentação dos conteúdos e a temporalidade dos objetivos, dentre outros elementos educacionais que permitam aos alunos (com ou sem deficiência) que não se beneficiam do modelo convencional de ensino as devidas oportunidades de acessar e aprender os conteúdos organizados no currículo. Desenvolver trabalhos por meio de grupos produtivos, dar mais tempo ao aluno para concluir a atividade, modificar a organização didática, fornecendo exemplos concretos, expor os alunos a vivências e experiências para formulação de conceitos são claros exemplos de ações de flexibilização e adequação curricular (NEVES; LEITE, 2013).

Diferentemente, a adaptação curricular focaliza a organização escolar e os serviços de apoio, os quais proporcionam condições estruturais que possam favorecer o planejamento curricular da sala de aula, implicando mudança significativa no próprio plano curricular e na proposta de currículo, pautado em planejamento educacional diferenciado dos demais alunos. Essa modalidade de ajuste curricular é implementada quando as ações de flexibilização e adequação não atendem às necessidades educacionais de pessoas com graves comprometimentos (MINETTO, 2008) e/ou com severas limitações decorrentes da condição da deficiência e/ou do transtorno (as quais inviabilizam, por sua vez, o acesso ao currículo) (ARANHA, 2004; BRASIL, 1999), exigindo a proposição de um currículo especialmente planejado para esse aluno. As formulações de currículos específicos para quadros de deficiência intelectual grave e de autismo típico podem ser consideradas adaptações, na medida em que toda a estruturação curricular produzida se dá em função das especificidades do aluno.

Nesse contexto, observa-se que poucas investigações retrataram de fato as dimensões curriculares e o processo de escolarização formal de pessoas com autismo (GOMES; MENDES, 2010), as quais se configuraram majoritariamente como estudos de casos (KERN, 2005; RUBLESCKI, 2004; SERRA, 2004), apresentando apontamentos gerais dos ajustes curriculares implementados e que não poderiam ser tomados como parâmetro para avaliação das estratégias e políticas educacionais adotadas em larga escala (para essa população). Apesar da escassez de literatura sobre a temática, defende-se aqui uma perspectiva de educação inclusiva (ARANHA, 2004; CAIADO; LAPLANE, 
2009; ECHEITA, 2010; LEITE; MARTINS; PEREIRA, 2007; MINETTO, 2008; ZANATA, 2004) que preconiza a inclusão desse alunado no contexto escolar comum e o respectivo acesso ao currículo, na medida em que se ofereçam respostas educacionais diferenciadas e efetivas frente às limitações impostas pelo autismo, as quais devem incidir nas diversas esferas do contexto escolar, desde aspectos estruturais da sala de aula até mudanças no currículo. Ainda, em alguns casos de autismo, advoga-se pela adaptação curricular, que deve apontar para reformulações substanciais nos conteúdos do currículo, com vistas a favorecer as máximas condições educacionais para a aprendizagem acadêmica do aluno, a autonomia e o exercício da cidadania.

Devido ao fato de as políticas de inclusão educacional garantirem, democraticamente, o acesso de alunos com diferentes características e demandas educacionais aos espaços e conteúdos escolares ditos comuns (MANTOAN, 1997; MAZZOTTA, 1999), a questão dos ajustes curriculares torna-se elemento crucial para o aluno, independentemente de suas características. Nessa condição, a apropriação dos conhecimentos científicos pode ocorrer por meio de ajustes de acesso ao currículo (no qual são providos/modificados recursos espaciais, materiais, pessoais ou de comunicação, para que o aluno entre em contato com o currículo formal), ou de adaptações individualizadas de currículo (abarcam quaisquer ajustes nos diferentes elementos da proposta educativa, almejando atender satisfatoriamente às necessidades educativas) (DÍAZ-CANEJA; APOCADA, 2008; PACHECO, 2009).

Essa proposta educacional sobre as dimensões curriculares tem garantido o acesso e o sucesso acadêmico a diversos alunos, especialmente àqueles que apresentam limitações sensoriais, motoras, intelectuais, comunicacionais, transtornos globais do desenvolvimento e problemas de comportamento, considerados, em sua maioria, incapazes de aprender e dominar conteúdos escolares. Assim sendo, o currículo destitui-se de uma condição de barreira educacional, constituindo-se, nesse processo, como elemento facilitador da aprendizagem (GOMES, 2007; ECHEITA, 2010).

Contudo, a escolarização formal (bem como a aprendizagem dos conteúdos acadêmicos) de alguns alunos com transtornos globais do desenvolvimento, especificamente com autismo típico, tem sido um desafio atual e recorrente para a área da educação. A inserção desse público no contexto escolar regular, preconizada em diversas políticas públicas e decretos — com ênfase na Lei n ${ }^{\circ} 12.764$ de 27 de 
dezembro de 2012, que definiu as políticas nacionais para proteção dos direitos da pessoa com transtorno do espectro autista e abrangeu diversos segmentos sociais (inclusive a educação) (BRASIL, 2012) - suscitou problematizações importantes sobre o fazer docente (BRAGA, 2002; LAGO, 2007) e a implementação de um currículo frente aos prejuízos globais do desenvolvimento que decorrem do autismo, os quais comprometem diversas áreas (tais como linguagem, comunicaçãoe cognição), logo, dificultandoqueessealuno fiqueatento, comunique-se, abstraia e aprenda muitos dos conteúdos previstos no currículo formal (BRIDI; FORTES; BRIDI FILHO, 2006).

Investigado inicialmente por Kanner (1943), o autismo típico sofreu reformulações terminológicas e de critérios diagnósticos ao longo dos anos, sendo definido como Transtorno Global do Desenvolvimento (TGD) pela quarta versão revisada do Manual Diagnóstico e Estatístico de Transtornos Mentais (DSM-IVTR) (ASSOCIAÇÃO AMERICANA DE PSIQUIATRIA, 2002) e recentemente reformulado pela Associação Americana de Psiquiatria como Transtorno do Espectro Autista (TEA) (MECCA et al., 2012). $\mathrm{O}$ autismo típico é caracterizado por manifestações comportamentais que incluem déficits qualitativos na interação social e na comunicação, padrões de comportamento repetitivos e estereotipados e repertório restrito de interesses e atividades (GADIA; TUCHMAN; ROTTA, 2004), sendo identificados tais comprometimentos antes dos três anos de idade (CAMARGO; BOSA, 2009).

No domínio social, as dificuldades na interação interpessoal podem manifestar-se como isolamento, comportamento social impróprio, pobre contato visual, dificuldade em participar de atividades em grupo, indiferença afetiva, ou demonstrações inapropriadas de afeto e falta de empatia (GADIA; TUCHMAN; ROTTA, 2004). Na área da linguagem e comunicação, observa-se que os padrões de comunicação (tanto verbal como não verbal) diferem significativamente dos padrões habituais, com predomínio de desvios semânticos e pragmáticos (tais como ecolalia e afasia nominal) (SANTO; COELHO, 2006). No que tange à cognição e ao comportamento, pessoas com autismo podem apresentar rigidez de pensamento e de comportamento, reduzida abstração, comportamentos ritualísticos e obsessivos, dependência de rotinas, déficits intelectuais, ausência de jogo imaginativo, inflexibilidade à mudança no ambiente habitual e comportamentos agressivos e autolesivos (SANTO; COELHO, 2006). 
Dado que as políticas de inclusão educacional implicaram grandes desafios à educação, nas diversas dimensões (inclusive no currículo) (LOPES, 2006; MANTOAN, 1997), múltiplas produções acadêmicas em teses e dissertações foram fomentadas nessa direção, as quais possibilitaram articulação — em âmbito teórico, reflexivo e pragmático — sobre os processos que abarcam a escolarização formal de diferentes tipos de aluno, com foco especial em alunos com deficiência e TGD (como no caso do autismo). A produção científica sobre os processos educacionais inclusivos envolveu a organização de grandes grupos de pesquisadores entre universidades, o incentivo financeiro e político às pesquisas que explorassem aspectos educacionais para os alunos ditos "especiais", a criação de periódicos nacionais voltados à Educação Especial e a abertura de programas de pósgraduação na área da Educação Especial, sendo, em 1978, aberto o primeiro programa de pós-graduação, sediado na Universidade Federal de São Carlos, em resposta a implementação de um sistema de educação especial pelo governo do Estado de São Paulo, o qual requeria a capacitação de recursos humanos e agentes multiplicadores nos cursos de Pedagogia habilitados para Educação Especial (BUENO, 1993; MENDES, 2010).

Uma parte do resultado desses esforços acadêmicos encontra-se nos 3.834 estudos (aproximadamente) do banco de teses e dissertações da Coordenação de Aperfeiçoamento do Ensino Superior (BTD-CAPES), os quais discorrem sobre múltiplas temáticas da inclusão educacional com diferentes populações de alunos com deficiência, transtornos globais do desenvolvimento, dentre outros.

Considerando as peculiaridades do aluno com autismo típico, a proposta de inclusão educacional no contexto escolar comum e o currículo, este estudo teve como objetivo mapear a produção acadêmica nacional, disponível no BTD-CAPES, sobre o processo de escolarização formal do aluno com autismo, especialmente no que se refere às suas dimensões curriculares. Pretende-se, assim, oferecer visão panorâmica das investigações sobre tal temática e sinalizar os caminhos possíveis para a produção do conhecimento científico nessa área tão desafiadora, que é a educação formal, e do acesso ao currículo para alunos com autismo. 


\section{MÉTODO}

Este trabalho é delineado como estudo do estado da arte, cujo objetivo foi mapear e discutir a temática em pauta no que concerne à produção acadêmica em diferentes áreas do conhecimento. Ao explorar os diversos aspectos envolvidos e as ênfases conferidas a determinados contextos históricos e lugares, o estado da arte oferece um panorama sobre quais são as formas e as condições sob as quais se tem dado a produção científica (em dissertações, teses, artigos e anais de congressos). Reconhecidos pelo recurso metodológico de caráter inventariante e descritivo, à luz de categorias e de facetas que os caracterizam, o estado da arte propicia visão abrangente sobre o fenômeno abordado e os decorrentes desdobramentos científicos que o perpassaram durante o período histórico analisado (FERREIRA, 2002).

Para a revisão sistemática da literatura nacional sobre inclusão educacional do aluno com autismo e dos aspectos relativos ao currículo acadêmico, procedeu-se à busca bibliográfica no portal do BTD-CAPES, durante o período de 12 a 31 de outubro de 2012, sendo selecionados apenas os trabalhos depositados até a referida data. Tendo em vista abranger um período representativo da produção, derivada de teses e dissertações, todos os estudos compreendidos de janeiro de 1987 a dezembro de 2011, resultantes do rastreamento dos unitermos, foram considerados inicialmente válidos para análise.

Os unitermos aplicados nessa revisão foram "autismo", "autista", "inclusão", "inclusiva", "educação", "currículo", "adequação", "adaptação" e "modificação", os quais foram permutados em expressões de dois a três termos para busca na referida base eletrônica, ou seja: "autista inclusão", "autista inclusão educação", "autista inclusão currículo", "autista inclusiva", "autista inclusiva educação", "autista inclusiva currículo", "autismo inclusão", "autismo inclusão educação", "autismo inclusiva educação", "autismo inclusão currículo", "autismo inclusiva currículo", "autista currículo", "autismo currículo", "autismo adequação", "autismo adequação currículo", "autismo adaptação", "autismo adaptação currículo", "autista adequação", "autista adequação currículo", "autista adaptação", "autista adaptação currículo", "autismo currículo educação", "autista currículo educação", "autismo modificação", "autismo modificação currículo", "autista modificação" e "autista modificação currículo". Essas múltiplas combinações dos unitermos visaram a oferecer o rastreamento do maior número possível de 
estudos que explorassem a temática da escolarização formal do aluno com autismo, bem como as suas questões curriculares, tais como adaptação, adequação e modificação curricular.

A princípio, o levantamento abarcou todos os estudos exibidos no portal da BTD-CAPES, os quais derivaram da busca permutada dos unitermos, independentemente de os estudos encontrados serem repetidos. Para cada estudo selecionado no levantamento, coletaram-se informações adicionais quanto ao ano de defesa da tese/dissertação, modalidade (mestrado, doutorado ou profissionalizante), universidade, região do país, programa a que se vinculava, grande área de conhecimento, autor, título e resumo. No segundo momento, os resultados integraram uma única base de dados, e os estudos indicados em mais de uma expressão de termos (ou seja, repetidos) foram contabilizados em apenas uma delas (sendo excluído nas demais), configurando assim o levantamento real de quais e quantos estudos articulavam-se à temática.

Em um primeiro procedimento de análise, os estudos foram categorizados em dois grandes grupos designados como "relativos" e "não relativos", sendo definidos a partir dos seguintes critérios: (1) o termo "autismo" ou "autista" deve estar citado no título e/ ou no resumo; (2) os estudos devem expressar ou ter relação com contextos escolares ou ambientes regulares e/ou específicos de ensino formal (escola, instituições especializadas, entre outros); e (3) que remetessem, no resumo, de forma geral e/ou específica, a aspectos do currículo acadêmico para essa população.

Somente estudos que atenderam necessariamente aos três critérios fizeram parte da categoria "relativos", sendo os demais avaliados como "não relativos". Ressalta-se que, por decisão dos autores e para que se mantivesse o foco no aluno com autismo típico, teses e dissertações relacionadas a transtornos globais de espectro autista, tais como Asperger e Rett, não foram enquadradas nos estudos "relativos".

O segundo procedimento de análise consistiu na descrição dos estudos englobados na categoria "relativos", a partir do cruzamento dos dados adicionais (ano, modalidade, universidade, região do país, área/programa e grande área) por meio do software Statistical Package for Social Science, versão 18 (SPSS $\left.{ }^{\circledR}\right)$, bem como da categorização dos conteúdos dos resumos. 
Enfatiza-se que essa revisão tem caráter majoritariamente descritivo do cenário da produção acadêmica do Brasil ao longo dos últimos 24 anos, no que tange à inclusão escolar e escolarização formal do aluno com autismo, com enfoque nos aspectos curriculares. Logo, não há pretensão de esgotar a complexa e desafiadora temática que se impõe à educação, abrangendo outras dimensões acadêmicas.

\section{RESULTADOS E DISCUSSÃO}

O levantamento inicial, resultante da busca combinada dos unitermos, apontou 483 registros de possíveis produções acadêmicas. A partir da compilação desses dados e exclusão de estudos repetidos, foi observada a redução de $67,49 \%$ dos registros, computando-se 157 estudos que poderiam envolver discussões, reflexões e/ou intervenções relacionadas às questões curriculares e à escolarização formal do aluno com autismo.

Nessa amostra real ( $\mathrm{n}=157), 106(67,5 \%)$ foram categorizados como "não relativos", quer seja por não preencherem os critérios estabelecidos, quer seja por abrangerem especificamente investigações sobre TGD com características de espectro autista. A Tabela 1 apresenta a classificação por categoria temática dos estudos considerados não relativos.

O refinamento dos estudos definidos como "relativos" sugere que a maioria das investigações ainda tem privilegiado aspectos teórico-aplicados específicos aos TGD de espectro autista (tais como Asperger), análises abrangentes da inclusão do aluno com deficiência (sem especificação do aluno com autismo) e intervenções de cunho terapêutico para esse aluno, diluindo o caráter de importância científica que lhe é devido quando são abordados escolarização formal e currículo. 
Tabela 1 - Distribuição dos estudos considerados não relativos, por categoria temática

\begin{tabular}{|c|c|c|}
\hline Categorias & Frequência & Distribuição \\
\hline Aspectos familiares do aluno com autismo & 11 & $10,40 \%$ \\
\hline Características psicológicas do aluno da Educação Especial & 7 & $6,60 \%$ \\
\hline Estudos epidemiológicos sobre 0 autismo & 2 & $1,90 \%$ \\
\hline Escalas psicométricas & 9 & $8,50 \%$ \\
\hline Filosofia/Ciência & 7 & $6,60 \%$ \\
\hline $\begin{array}{l}\text { Inclusão de alunos com deficiências, TGD e } \\
\text { dificuldades de aprendizagem }\end{array}$ & 14 & $13,20 \%$ \\
\hline Intervenção com a pessoa com autismo & 12 & $11,30 \%$ \\
\hline Processos de construção da Educação Inclusiva & 7 & $6,60 \%$ \\
\hline Professor na perspectiva da Educação Inclusiva & 13 & $12,30 \%$ \\
\hline Revisão Literatura sobre Autismo & 1 & $0,90 \%$ \\
\hline TGD espectro autista & 23 & $21,70 \%$ \\
\hline
\end{tabular}

Fonte: Autores

Os estudos considerados "relativos" corresponderam a $32,5 \%(\mathrm{n}=51)$ dos registros iniciais, sendo os dados adicionais (tais como ano de publicação, programa, universidade, entre outros) e os conteúdos dos resumos analisados pelos pesquisadores. Enquanto a análise estatística oportunizou descrever a configuração do cenário brasileiro na produção acadêmica sobre as questões curriculares, a análise temática dos resumos complementou-a, revelando sobre quais dimensões da escolarização há maior interesse, descrição e análise. 
Figura 1 - Distribuição Evolução temporal da produção brasileira sobre escolarização formal do aluno com autismo, por modalidade de pós-graduação

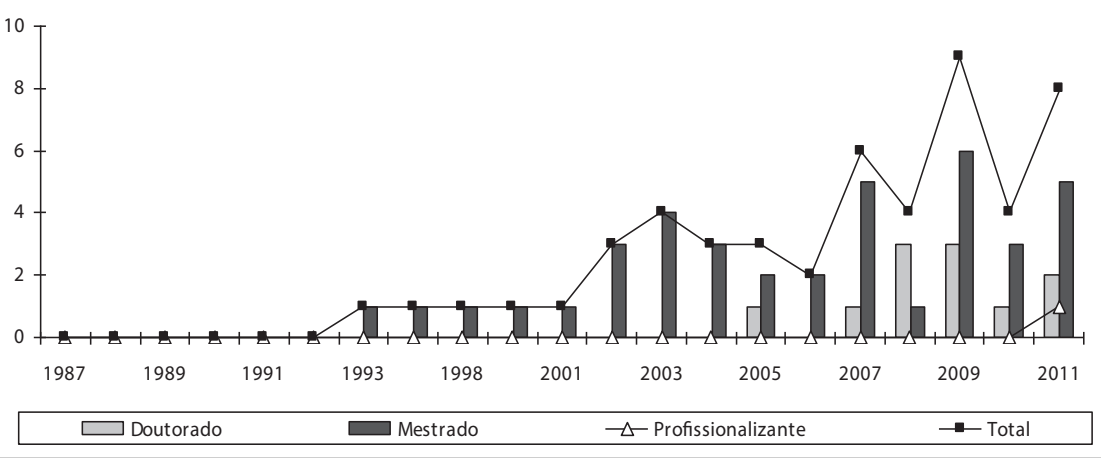

Fonte:Autores

De acordo com a Figura 1, observa-se a inexistência de investigações em teses e dissertações sobre inclusão educacional da pessoa com autismo até 1992, momento em que se iniciaram reduzidos estudos (especialmente em nível de mestrado). Esse quadro demonstra que a produção científica sobre escolarização do aluno com autismo refletia as constantes mudanças históricas nas políticas de inclusão educacional: inexpressiva até o início da década de 90, a temática da inclusão escolar da pessoa com deficiência e com autismo começou a ganhar relevância e visibilidade com a articulação dos movimentos sociais de direitos humanos da pessoa com deficiência, Declaração da Educação como Direito de Todos em 1990, Declaração de Salamanca de 1994 e promulgação da LDB 9.394/96 (BRASIL, 1996), condição que pode ter corroborado para o surgimento das primeiras discussões acadêmicas sobre inclusão do aluno com autismo no ensino regular.

Com o advento das políticas de inclusão social e educacional (MAZZOTTA, 1999), as discussões pleiteadas pelo movimento da Educação Inclusiva e a inserção da pessoa com autismo em salas regulares (MANTOAN, 1997), diversas produções acadêmicas foram fomentadas, especialmente a partir de 2001, com o intuito de responder aos questionamentos e inquietações escolares sobre os múltiplos aspectos que envolvem o aluno com autismo em contexto escolar comum. Assim, em 2002, houve um salto quantitativo desses estudos, favorecendo aumento nos anos posteriores (com ápice em 2009), ainda com algumas oscilações. 
Esse salto, provavelmente, foi alavancado pelas discussões acadêmicas recorrentes sobre Educação Inclusiva e efetivação das políticas de inclusão educacional de indivíduos que estavam marginalizados dos espaços e processos escolares formais. Ressaltase, ainda, que houve concentração dessas investigações no curso de mestrado, sendo que apenas em 2005 surgiram os primeiros estudos na modalidade de doutorado. Um dado interessante remete ao fato de que, embora seja recente a implantação do mestrado profissionalizante no país, encontrou-se um estudo de 2009, cuja preocupação foi investigar a inclusão educacional do aluno com autismo.

Apesar de o início das discussões sobre os processos inclusivos na educação remontar à década de 90 , a implementação das políticas educacionais, que de fato garantissem o acesso ao ensino formal para alunos com deficiência e autismo (particularmente), consolidouse somente a partir de 2000 (MATISKEI, 2004). Esse momento histórico pode ser considerado um marco importante para o início das pesquisas sobre as questões curriculares que abarcariam esse tipo de aluno, o que justifica, em certa medida, a produção acadêmica ainda incipiente.

A Figura 2 expressa a evolução temporal dos estudos vinculados a programas de pós-graduação em Educação, Psicologia e outras áreas afins, tais como Artes, Distúrbios da Comunicação, Informática e Educação Física. Os resultados indicam que a área de Educação (incluindo pós-graduações em Educação e Educação Especial) detém grande parte da produção acadêmica sobre o tema, incentivada desde as discussões iniciais sobre inclusão educacional na década de 90, demonstrando, assim, as investidas de programas nessa área para produção de conhecimento útil, reflexivo e prático, que atendesse às demandas sociais emergentes do professor diante do aluno com autismo. 
Figura 2 - Distribuição temporal da produção brasileira sobre escolarização formal do aluno com autismo, a partir da área de concentração dos programas de pós-graduação

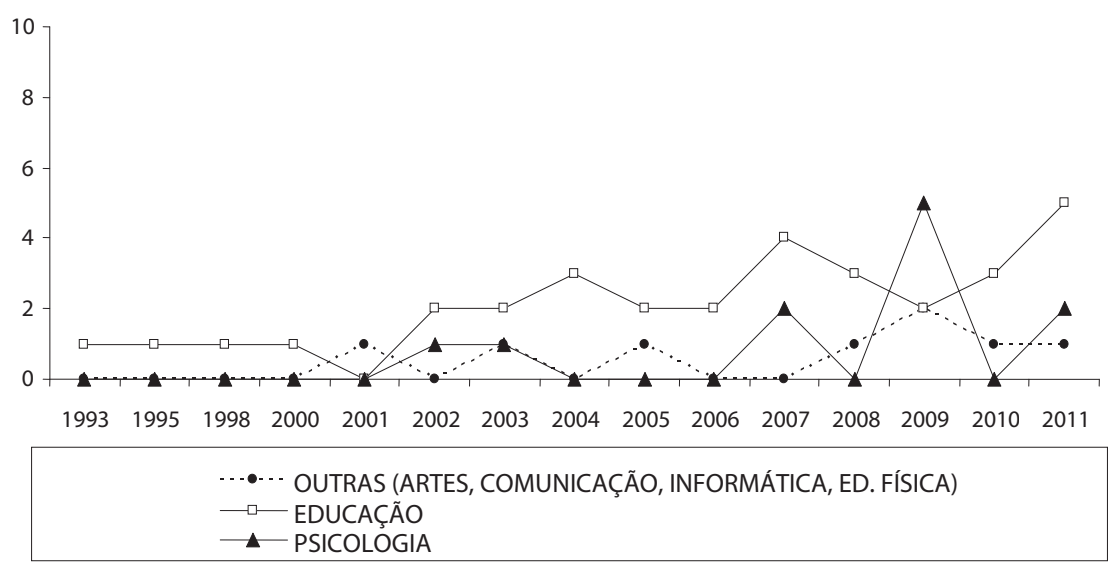

Fonte: Autores

Os estudos que abarcam tal temática e vinculam-se aos programas de Psicologia (os quais reúnem programas de Psicologia, Psicologia Clínica e Psicologia Experimental) mostraram-se inexpressivos até 2006, tendo aumento significativo a partir desse período. Esse dado pode ser um indicativo do maior envolvimento da área da Psicologia, a partir de 2006, na produção de conhecimento científico sobre os processos educacionais do aluno com autismo no ensino regular, bem como da relevância da interface com a educação, intentando contribuir para a inclusão plena desse tipo de aluno.

Áreas como a de Distúrbios da Comunicação, embora apresentem muitos estudos com crianças autistas (especialmente sob a perspectiva terapêtica), demonstram poucas pesquisas atreladas às esferas educacionais do aluno com autismo, o que manifesta os possíveis entraves de algumas áreas da ciência (e das respectivas atuações multidisciplinares) no contexto da educação, bem como a manutenção de modelo clínico de atendimento para esse aluno. As demais áreas (Informática e Educação Física) apresentam estudos esparsos no período em questão.

Ao cruzar as variáveis de ano e área do conhecimento, foi identificada a concentração desses estudos nas Ciências Humanas durante todo o período analisado, fato este decorrente da grande 
produtividade dos programas em Educação E Psicologia, bem como da especificidade da temática, a qual historicamente está atrelada às áreas das Humanidades.

Todavia, notou-se que as Ciências Exatas (especificamente Ciência da Computação e Informática) apresentam produções pontuais no período de 2002 a 2006, as quais investigam a interface da Tecnologia Computacional para educação do aluno com autismo, sugerindo que os múltiplos processos que envolvem inclusão educacional (e as possíveis adaptações curriculares) desses alunos perpassam as contribuições das mais diversas áreas do conhecimento humano. Ainda, as Ciências da Saúde exibiram poucos estudos relativos ao universo escolar, sendo esses, por sua vez, pautados em modelo terapêutico de atenção ao aluno com autismo. A Figura 3 expressa essas questões.

Figura 3 - Distribuição temporal da produção brasileira sobre a escolarização formal do aluno com autismo, a partir das grandes áreas do conhecimento

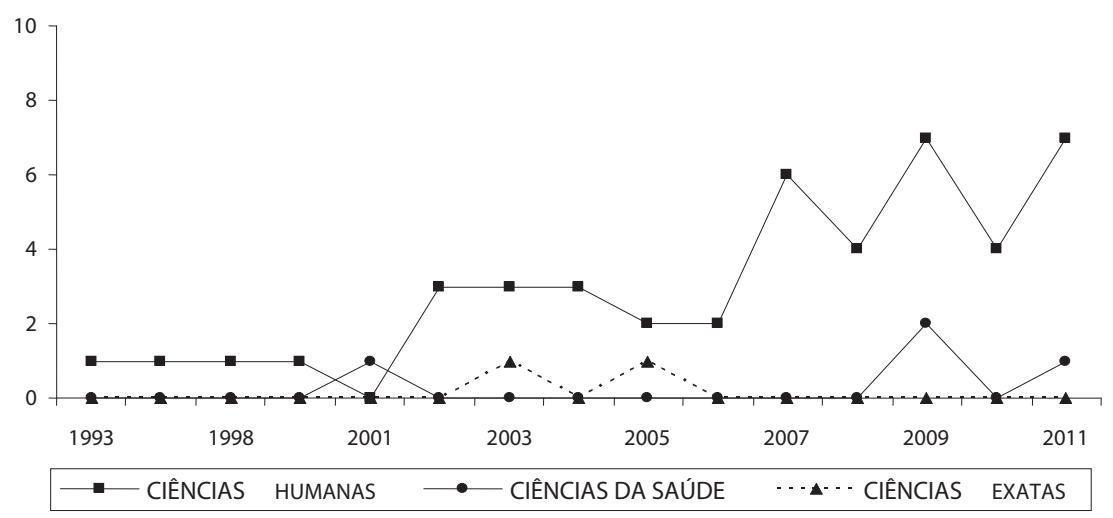

Fonte:Autores

A produção acadêmica nacional, distribuída por centros universitários, está devidamente expressa na Figura 4. 
Figura 4 - Distribuição quantitativa da produção brasileira sobre a escolarização formal do aluno com autismo, a partir das universidades

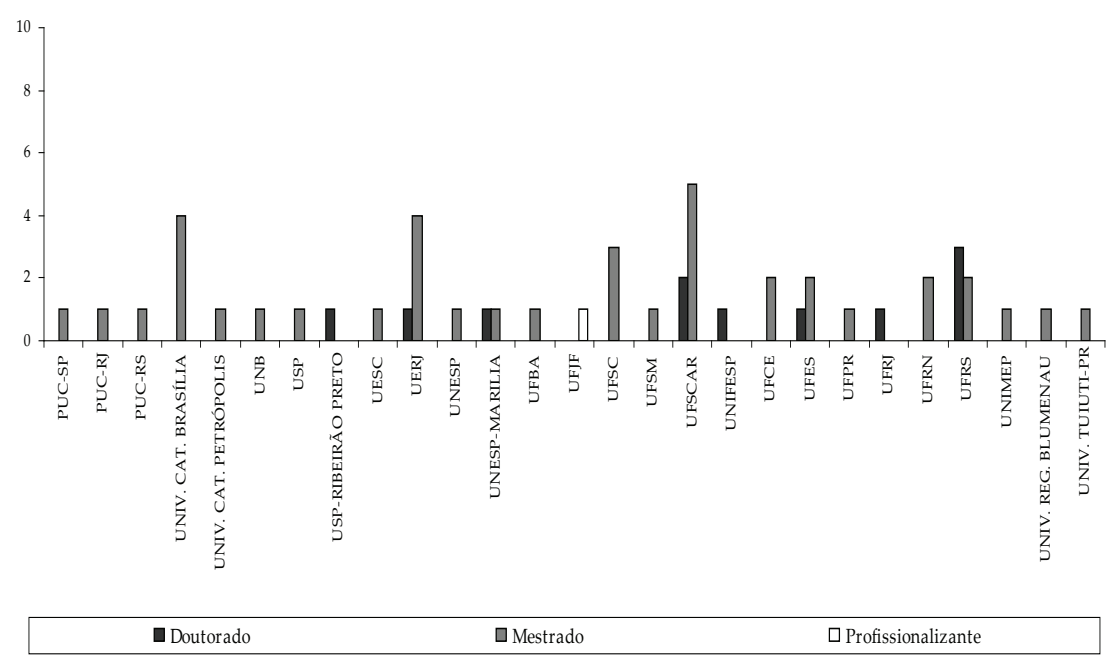

Fonte:Autores

Observa-se que os centros acadêmicos de maior produção localizam-se na região sudeste $(54,90 \%)$ e no sul $(25,49 \%)$ do país, em detrimento dos demais encontrados no centro-oeste e nordeste (ambos com 9,80\%), o que se assemelha aos achados de Vianna et al. (2011) em seu estudo sobre gênero, sexualidade e educação. A região norte do Brasil não apresentou nenhum estudo. Simultaneamente, as universidades públicas representaram a maior parcela da produção acadêmica, seguidas das universidades católicas, o que aproxima este estudo ao de Viana et al. (2011) quanto à prevalência de estudos por categorias de instituições de ensino superior.

Os resultados obtidos demonstram que existem programas de pós-graduação com elevado índice de produção. A Universidade Federal de São Carlos (UFSCar) concentra grande parte (13,72\%), uma vez que possui um programa de estudos de pós-graduação específico em Educação Especial, o qual versa sobre tais problemáticas, sendo o primeiro programa a produzir um estudo sobre o aluno com autismo em contexto escolar (BAZOTI, 1993).

Concomitantemente à UFSCar, Brasília se caracteriza como outro polo nessa produção acadêmica, abarcando dois centros universitários: Universidade de Brasília (UNB) e Universidade 
Católica de Brasília, os quais se têm dedicado ao estudo dos processos de inclusão educacional da pessoa com autismo, contudo não há grande enfoque no aspecto curricular.

A Universidade Estadual do Rio de Janeiro (UERJ) e a Universidade Federal do Rio Grande do Sul (UFRS) também indicam elevada quantidade de estudos relacionados à inclusão educacional do aluno com autismo, porém, de formas distintas: enquanto a produção acadêmica na UERJ está atrelada apenas ao tradicional programa de pós-graduação em Educação, a UFRS tem distribuído esses estudos em seus diferentes programas de mestrado e doutorado (áreas da Psicologia, Informática e Educação), indicando sua preocupação em incentivar pesquisas multidisciplinares para o desenvolvimento acadêmico-prático dessa temática.

Brandão (2005) afirma que a distribuição irregular da produção acadêmica por polos universitários pode sinalizar que essas pesquisas surgiram dos interesses particulares dos mestrandos e doutorandos, o que, a princípio, não deve ser tomado como aspecto negativo. Todavia, pode-se especular que esses dados apontem para a inexistência ou reduzida investigação da escolarização formal do aluno com autismo, vinculada a grupos de pesquisas (intra ou interinstitucional), bem como à assistematicidade dessa produção pelos orientadores nas pós-graduações. Brandão (2005) ainda reforça que a excessiva dispersão e a fragmentação de pesquisas - sem que ocorra continuidade, integração e sistematização desses saberes - possam promover superficialidade e entraves na acumulação do conhecimento científico produzido.

A Tabela 2 demonstra a distribuição dos estudos relativos por categorias temáticas, as quais retratam as diferentes dimensões abordadas e investigadas nos estudos conduzidos em programas de pós-graduação no Brasil. 
Tabela 2 - Distribuição dos estudos considerados relativos, por categoria temática

\begin{tabular}{|c|c|c|}
\hline Categorias & Frequência & Distribuição \\
\hline & 1 & $1,96 \%$ \\
\hline \multicolumn{3}{|l|}{ Avaliação psicológica do aluno com autismo } \\
\hline & 11 & $21,57 \%$ \\
\hline \multicolumn{3}{|l|}{ Currículo para 0 aluno com autismo } \\
\hline & 2 & $3,92 \%$ \\
\hline \multicolumn{3}{|l|}{ Diagnóstico e encaminhamento do aluno com autismo } \\
\hline & 1 & $1,96 \%$ \\
\hline \multicolumn{3}{|l|}{ Formação docente para autismo } \\
\hline & 13 & $25,49 \%$ \\
\hline \multicolumn{3}{|l|}{ Interações na Educação Inclusiva com o aluno com autismo } \\
\hline & 3 & $5,88 \%$ \\
\hline \multicolumn{3}{|l|}{ Intervenção com o aluno com autismo } \\
\hline \multirow{2}{*}{$\begin{array}{l}\text { Percepção e ação docente quanto ao processo de inclusão do } \\
\text { aluno com autismo }\end{array}$} & 5 & $9,80 \%$ \\
\hline & 4 & $7,84 \%$ \\
\hline \multicolumn{3}{|l|}{ Pesquisas com aluno com autismo e com outras deficiências } \\
\hline & 7 & $13,73 \%$ \\
\hline \multicolumn{3}{|l|}{ Práticas pedagógicas para aluno com autismo } \\
\hline & 1 & $1,96 \%$ \\
\hline \multicolumn{3}{|l|}{ Reflexões sobre a inclusão do aluno com autismo } \\
\hline & 2 & $3,92 \%$ \\
\hline \multicolumn{3}{|l|}{ Revisão da literatura sobre escolarização da pessoa com autismo } \\
\hline & 1 & $1,96 \%$ \\
\hline Sistema e ducacional para 0 aluno com autismo & & \\
\hline
\end{tabular}

Fonte:Autores

Nota-se que $25,49 \%$ dos estudos têm investido na discussão e na análise das interações interpessoais entre o aluno com autismo e os diversos agentes escolares (professores, pares e funcionários), revelando a preocupação acadêmica de se problematizar e implementar ações, no âmbito escolar, que promovam processos facilitadores da interação social e de interlocução/comunicação desse tipo de aluno. Infere-se também que essa expressiva produção acadêmica pode ser uma tentativa de responder às demandas escolares vigentes, especialmente no que tange às suas dificuldades de interação social quando inserido no espaço escolar comum. 
O segundo tema mais recorrente refere-se aos aspectos curriculares, os quais constituem um dos principais interesses deste trabalho, correspondendo a $21,57 \%$ do total de estudos relativos. Foi observado que, embora esse tema tenha aparecido enquanto categoria representativa, as investigações que discorreram sobre dimensões curriculares ainda são incipientes e pioneiras, o que converge com os indicativos de Gomes e Mendes (2010) e de Bride, Fortes e Bridi Filho (2006), de que o fenômeno da escolarização formal e o questionamento sobre o currículo para esse alunado são relativamente recentes no cenário da Educação (mesmo que tenham sido preconizados anteriormente pela LDB 9.394/1996 e pelos Parâmetros Curriculares Nacionais de adaptações curriculares) e ainda demandam maior produção e sistematização do conhecimento sobre os processos que o perpassam.

Ao se investigar os tipos de pesquisa presentes nessa categoria, constatou-se que, em sua maioria, concentraram-se em estudos de relatos de caso único, expressando duas dimensões desse campo recente de investigação: (1) que os referidos estudos podem se configurar como modelos importantes para implementação de programas curriculares para alunos com autismo (KERN, 2005); ou (2) que revelam a carência (e, por conseguinte, a necessidade) de investigações em larga escala que possam de fato avaliar as estratégias e ajustes curriculares adotados para esse público (GOMES; MENDES, 2010).

Adicionalmente, percebeu-se que os estudos da referida categoria (currículo para aluno com autismo), ao discorrerem sobre as dimensões curriculares, enfatizavam a importância de atrelar os conteúdos curriculares às estratégias pedagógicas e efetividade de programa de currículo funcional natural. Esse dado revela, ao menos, dois aspectos interessantes no que tange aos ajustes curriculares para alunos com autismo.

O primeiro aspecto remete à discrepância entre a proposição de adaptação curricular prevista nos documentos oficiais, como a LDB 9.394/1996 e os Parâmetros Curriculares Nacionais de adaptações curriculares, e as instâncias educacionais sobre as quais, de fato, incidem essas políticas, como podemos notar a partir dos estudos de Braga (2002) e Lago (2007). Nessas pesquisas, em geral, os ajustes curriculares compreenderam apenas a modificação das práticas pedagógicas dos professores - como a implementação de recursos didáticos diferenciados, formas de apresentação do conteúdo do currículo, capacitação de recursos humanos e 
reformulação da temporalidade dos objetivos de ensino — sem que necessariamente se propusesse uma adaptação do currículo comum ou planejamento curricular diferenciado, com vistas a atender as especificidades do aluno.

Logo, as ações consideradas "adaptações curriculares" não recaem diretamente sobre o currículo, mas sobre outras instâncias envolvidas no seu ensino (tais como os materiais, estratégias de ensino, os recursos didáticos, dentre outros). Esse quadro demonstra certo desencontro entre a adaptação curricular enquanto política educacional (que admite a reestruturação de currículos para atender as particularidades do alunado) e as ações que são implementadas na realidade escolar quando se trata da escolarização formal do aluno com autismo (as quais abrangem apenas uma parcela das possibilidades educacionais, nesse caso, apenas os aspectos pedagógicos).

$\mathrm{O}$ segundo aspecto a ser considerado refere-se à proposta de que a escolarização formal do aluno com autismo preconize o currículo funcional, como se nota no estudo de Cuccovia (2003), por exemplo. Essa ênfase no ensino de habilidades funcionais (no contexto escolar), que facilitem a vivência-convivência do aluno com autismo em diversos ambientes, pode revelar duas situações: 1) as dificuldades que o autismo estabelece para a emancipação desse aluno e, nessa direção, a importância de que a escola promova a aprendizagem das competências consideradas importantes, a fim de garantir a maior autonomia possível desse sujeito; e 2) a dificuldade e negligência do atual sistema educacional em oferecer condições suficientes de acesso, permanência e êxito acadêmico para alunos com essas características, especialmente quando são abordados os conhecimentos sistematizados no currículo.

Estudos sobre as práticas pedagógicas correspondem a $13,73 \%$ da totalidade da produção acadêmica sobre a escolarização formal da pessoa com autismo, constituindo-se enquanto a terceira temática mais recorrente quando se investiga seu processo educacional formal. Sobreposta à categoria temática da "Percepção e ação docente no processo de inclusão do aluno com autismo", esses estudos tendem a reforçar a relevância da prática pedagógica na educação formal do aluno com autismo, possibilitando que os conteúdos acadêmicos previstos no currículo, ora tão distantes desse aluno, por meio da mediação docente, sejam alcançados e apropriados por eles. 
As demais categorias temáticas apontam para pesquisas pontuais, com ênfases e objetos de estudos diferenciados, o que indica que outros aspectos do contexto escolar do aluno com autismo ainda demandam maior aprofundamento e investigação.

Defende-se, então, que pesquisas futuras poderão explorar, aprofundar e propor possibilidades educacionais de acesso e aprendizagem dos conteúdos curriculares formais para alunos com autismo, visando a culminar em um processo verdadeiramente inclusivo, ou, como enfatizam Fuente e Torrijo (2011), em um processo de fato educacional, pois a educação só será educação quando for plenamente inclusiva. Entretanto, para que se avance a investigação científica nessa temática, faz-se necessário identificar o que já se tem produzido, conforme aponta Saviani (1983, p.51), “[...] se não se domina o já conhecido não é possível detectar o que não é conhecido [...]", vislumbrando-se, a partir de então, novas possibilidades no âmbito das pesquisas sobre escolarização formal do aluno com autismo.

\section{CONSIDERAÇÕES FINAIS}

Os resultados apresentados neste estado da arte — longe de quaisquer ambições de esgotar a totalidade e a complexidade que se impõem à escolarização formal do aluno com autismo e as questões curriculares pertinentes - almejam oferecer visão panorâmica da produção acadêmica nacional, indicando algumas das dimensões que configuram o cenário dessa inclusão educacional. Articulando elementos de ordem histórica com as de políticas educacionais aplicadas à pessoa com autismo, foi sistematizado quando e como a produção acadêmica de estudos vinculados aos programas de pós-graduação tem corroborado e respondido às demandas da área da educação, quer seja no aspecto teórico-reflexivo, quer seja no contexto aplicado.

Percebe-se que ainda há poucas pesquisas sobre o processo educacional complexo e emblemático do aluno com autismo, o que requer maior articulação das instâncias que produzem e elaboram o conhecimento científico (ou seja, as universidades). É preciso, então, que se formem mais grupos de pesquisa e que se implemente a continuidade sistemática de estudos sobre o tema, para se articular um corpo de conhecimento substancial sobre as múltiplas dimensões (teóricas e aplicadas), que constituem o fenômeno da educação 
formal de alunos com comprometimentos globais nas áreas do desenvolvimento, como ocorre no caso do autismo típico.

A temática do acesso e da apropriação dos conteúdos do currículo pelo aluno com autismo, embora já presente em alguns estudos, ainda exige maior investimento dos pesquisadores da educação e áreas afins, para que, mediada pela investigação científica, possam ser vislumbrados caminhos possíveis para sua escolarização plena e bem-sucedida. Sabe-se que, para o aluno com autismo, infelizmente, o currículo ainda é uma barreira educacional difícil de ser transposta, quer seja pelas limitações decorrentes do autismo, quer seja pelo sistema educacional, que inviabiliza tal acesso, quer seja por outros fatores; no entanto, ajustes curriculares, aliados a práticas pedagógicas eficazes, podem possibilitar aprendizagem dos conhecimentos nele preconizados.

Dentre os muitos passos que precisam ser dados na superação do atual quadro da escolarização formal do aluno com autismo, a produção do conhecimento científico robusto e potencialmente útil configura-se como um dos mais importantes. Nessa direção, foi apresentado um cenário científico sobre a escolarização formal do aluno com autismo e as respectivas questões de currículo, para que, oferecido esse passo inicial, possam ser dados outros no avanço desse conhecimento, o qual deve culminar em um processo verdadeiramente inclusivo.

\section{REFERÊNCIAS}

ASSOCIAÇÃO AMERICANA DE PSIQUIATRIA. Manual diagnóstico e estatístico de transtornos mentais: texto revisado. 4.ed. Porto Alegre: Artes Médicas, 2002.

ARANHA, M. S. F. Educação inclusiva: transformação social ou retórica. In: OMOTE, S. (Org.). Inclusão: intenção e realidade. Marília: FUNDEPE, 2004. p.37-60.

BAZOTI, S. P. Trabalho com crianças autistas: a busca de um caminho. 102f. 1993. Dissertação (Mestrado) - Programa de Pós-Graduação em Educação Especial, Universidade Federal de São Carlos, São Carlos, 1993.

BRAGA, M. C. B. A interação professor aluno em classe inclusiva: um estudo exploratório com criança autista. 200 f. 2002. Dissertação (Mestrado) - Programa de Pós-Graduação em Educação, Universidade Estadual Paulista, São Paulo, 2002.

BRANDÃO, Z. Pesquisa em educação. O olhar do nadador: do individual ao coletivo. Educação On Line, Rio de Janeiro, v.1, p.1-15, 2005.

BRASIL. Constituição (1988). Constituição da República Federativa do Brasil. Brasília, DF: Senado Federal, 1988.

BRASIL. Lei de Diretrizes e Bases da Educação Nacional, Lei no 9.394/96. Estabelece as diretrizes e bases da educação nacional. Disponível em: <http://portal.mec.gov.br/secad/arquivos/ pdf/ldb.pdf $>$. Acesso em: 5 set. 2012.

BRASIL. Ministério da Educação. Parâmetros curriculares nacionais - adaptações curriculares: 
estratégias de ensino para educação de alunos com necessidades educacionais especiais. Brasília: SEF; SEESP, 1999.

BRASIL. Conselho Nacional de Educação. Resolução CNE/CEB no 4/2010. Diretrizes curriculares nacionais gerais para a educação básica. Diário Oficial da União, Brasília, DF, 2010. BRASIL. Política Nacional de Direitos da Pessoa com Transtorno do Espectro Autista, Lei ${ }^{\circ}$ 12.764/2012, de 27 de dezembro de 2012. Brasília, DF. Institui a Política Nacional de Proteção dos Direitos da Pessoa com Transtorno do Espectro Autista. Disponível em: <http://www.planalto.gov.br/ccivil_03/_ato2011-2014/2012/lei/112764.htm>. Acesso em: 23 jan. 2014.

BRIDI, F. R. S.; FORTES, C. C.; BRIDI FILHO, C. A. Educação e autismo: as sutilezas e as possibilidades do processo inclusivo. In: ROTH, B. W. (Org.). Experiências educacionais inclusivas: programa de educação inclusiva - direito à diversidade. Brasília: Ministério da Educação, Secretaria de Educação Especial, 2006. Disponível em: <http://portal.mec.gov. $\mathrm{br} /$ seesp/arquivos/pdf/experiencias\%20inclusivas.pdf >. Acesso em: 10 jan. 2014.

BUENO, J. G. S. Educaşão especial brasileira: integração/segregação do aluno diferente. São Paulo: Educ, 1993.

CAIADO, K. R. M.; LAPLANE, A. L. F. Programa educação inclusiva: direito à diversidade — uma análise a partir da visão de gestores de um município-polo. Educação e Pesquisa, São Paulo, v.35, n.2, p.1-16, 2009.

CANDAU, V. M. Ênfase e omissões no currículo. Educação em Revista, Belo Horizonte, v.23, n.78, p.296-298, 2002.

CAMARGO, S. P. H.; BOSA, C. A. Competência social, inclusão escolar e autismo: revisão crítica da literatura. Psicologia \& Sociedade, Belo Horizonte, v.21, n.1, p.65-74, 2009. Disponível em: <http://www.scielo.com.br>. Acesso em: 15 out. 2012.

CAPELLINI, V. L. M. F. Avaliação das possibilidades do ensino colaborativo no processo de inclusão escolar do aluno com deficiência mental. 300f. 2004. Tese (Doutorado) - Programa de PósGraduação em Educação Especial, Universidade Federal de São Carlos, São Carlos, 2004.

CUCCOVIA, M. M. Análise de procedimentos para avaliação de interesses baseado em um currículo funcional natural e seus efeitos no funcionamento geral de indivíduos com deficiência mental e autismo. 2003. 150f. Dissertação (Mestrado) - Programa de PósGraduação em Educação Especial, Centro de Ciências Humanas, Universidade Federal de São Carlos, São Carlos, 2003.

DÍAZ-CANEJA, P.; APOCADA, R. R. Adaptações curriculares I. Inclusive, Educação e Cidadania, ano 5, nov. 2012. Disponível em: <http://www.inclusive.org.br>. Acesso em: 5 nov. 2012.

ECHEITA, G. Repensar políticas y prácticas para promover la educación inclusiva: barreras para el acceso, la permanencia, el aprendizaje y la participación de los jóvenes con discapacidad en educación secundaria. In: OREALC/UNESCO VII JORNADAS EDUCATIVAS DE COOPERACIÓNCON IBEROAMÉRICA SOBRE EDUCACIÓN ESPECIAL E INCLUSIÓN EDUCATIVA, 2010, Santiago de Chile. Anais..., Santiago de Chile, 2010, p.32-48.

FERREIRA, M. E. C. O enigma da inclusão: das intenções às práticas pedagógicas. Educação e Pesquisa, São Paulo, v.33, n.3, p.543-560, 2007. Disponível em: <http://dx.doi.org/10.1590/ S1517-97022007000300011>. Acesso em: 19 jan. 2014.

FERREIRA, N. S. A. As pesquisas denominadas "estado da arte". Educação \& Sociedade, Campinas, v.23, n.79, p.257-272, 2002. Disponível em: <http://www.scielo.com.br>. Acesso em: 19 nov. 2012.

FONSECA, K. A. Análise de adequações curriculares no ensino fundamental: subsídios para programas de pesquisa colaborativa na formação de professores. 126f. 2011. Dissertação 
(Mestrado) - Programa de Pós-Graduação em Psicologia do Desenvolvimento e Aprendizagem, Faculdade de Ciências, Universidade Estadual Paulista, Bauru, 2011.

FREITAS, L. C. de. Cultura e currículo: uma relação negada na política do sistema de progressão continuada no Estado de São Paulo. 300f. 2000. Tese (Doutorado) - Pontifícia Universidade Católica, São Paulo, 2000.

FUENTE, A. V.; TORRIJO, M. L. Personas com discapacidad: desde la exclusion a la plena cidadania. Intersticios Revista Sociológica de Pensamiento Crítico, Madri, v.5, n.1, p.123-155, 2011. Disponível em: < http://www.intersticios.es>. Acesso em: 05 out. 2012.

GADIA, C. A.; TUCHMAN, R.; ROTTA, N. T. Autismo e doenças invasivas de desenvolvimento. Jornal de Pediatria, Rio de Janeiro, v.80, n.2, p.83-94, 2004. Disponível em: $<$ http://www.scielo.com.br>. Acesso em: 10 out. 2012.

GARCIA, R. M. C. Políticas para a educação especial e as formas organizativas do trabalho pedagógico. Revista Brasileira de Educação Especial, Marília, v.12, n.3, p.299-126, 2006.

GOMES, N. L. Diversidade e currículo. In: BEAUCHAMP, J.; PAGEL, S. D.; NASCIMENTO, A. R. (Orgs.). Indagações sobre o currículo. Brasília: MEC/SEB, 2007. p.17-48.

GOMES, C. G. S.; MENDES, E. G. Escolarização inclusiva de alunos com autismo na rede municipal de ensino de Belo Horizonte. Revista Brasileira de Educaşão Especial, Marília, v.16, n.3, p.375-396, 2010. Disponível em: <http://www.scielo.br/scielo.php?script=sci_arttext\& pid=\$14135382010000300005\&lng=en\&nrm=iso > . Acesso em: 23 jan. 2014.

KANNER, L. Autistic disturbances of affective contact. The Nervous Child, Springfield, n.2., p.217-250, 1943.

KERN, C. Um processo considerado bem-sucedido de inclusão escolar e a síndrome do autismo: uma história com muitas vidas. 202f. 2005. Dissertação (Mestrado) - Programa de Pós-Graduação em Educação, Universidade Federal de Santa Catarina, Florianópolis, 2005.

LAGO, M. Autismo na escola: ação e reflexão do professor. 200f. 2007. Dissertação (Mestrado) - Programa de Pós-Graduação em Educação, Universidade Federal do Rio Grande do Sul, Porto Alegre, 2007.

LEITE, L. P.; MARTINS, S. E. O. A formação continuada como alternativa na operacionalização da pedagogia inclusiva. In: CONGRESSO ESTADUAL PAULISTA SOBRE A FORMAÇÃO DE EDUCADORES, 9., 2007, Águas de Lindóia. Livro eletrônico do IX Congresso Estadual Paulista sobre Formação de Educadores, 2007. p.14-24.

LEITE, L. P.; PEREIRA, L. G. A rede de apoio pedagógico como facilitadora para a educação inclusiva: uma proposta no município de Lençóis. In: REITORIA UNESP. (Org.). Caderno do Núcleo de Ensino - UNESP. São Paulo: Cultura Acadêmica, 2007. p.359-365.

LEITE, L. P.; SILVA, A. M. Flexibilização curricular. In: CAPELLINI, V. L. M. F.; RODRIGUES, O. M. P. (Orgs.). Formação de professores: práticas em educação inclusiva. Bauru: UNESP/FC, 2010. p.39-65.

LEITE, L. P.; BORELLI, L. M.; MARTINS, S. E. S. O. Currículo e deficiência: análise de publicações brasileiras no cenário da educação inclusiva. Educaşão em Revista, Belo Horizonte, v.29, n.1, 2013.

LOPES, A. C. Relações macro/micro na pesquisa em currículo. Cadernos de Pesquisa, São Paulo, v.36, n.129, p.619-635, dez. 2006. Disponível em: <http://dx.doi.org/10.1590/ S0100-15742006000300006>. Acesso em: 19 nov. 2012.

MAJÓN, D. G; GIL, J. R.; GARRIDO, A. A. Adaptaciones curriculares. Málaga: Ediciones Aljibe, 1997.

MICHAELIS. Moderno dicionário da lingua portuguesa, 2009. Disponível em: <http://michaelis. uol.com.br>. Acesso em: 01 set. 2012.

MANTOAN, M. T. H. A integração de pessoas com deficiência. São Paulo: Senac, 1997.

MATISKEI, A. C. R. M. Políticas públicas de inclusão educacional: desafios e perspectivas. 
Educar em Revista, Curitiba, n.23, p.185-202, 2004. Disponível em: < http://www.scielo.com. br>. Acesso em: 19 nov. 2012.

MAZZOTTA, M. J. S. Educação especial no Brasil: história e políticas públicas. São Paulo: Cortez, 1999.

MECCA, T. P. et al. Rastreamento de sinais e sintomas de transtornos do espectro do autismo em irmãos. Revista de Psiquiatria do Rio Grande do Sul, Porto Alegre, v.33, n.2, p.116-120, 2011. Disponível em: <http://www.scielo.br/scielo.php?script=sci_arttext\&pid=S010181082011000200009\&lng=en\&nrm=iso >. Acesso em: 23 jan. 2014.

MENDES, E. G. Breve histórico da educação especial no Brasil. Revista Educación y Pedagogía, Antioquia, v.22, p.93-110, 2010.

MINETTO, M. F. Currículo na educação inclusiva: entendendo esse desafio. 2.ed. Curitiba: Ibpex, 2008.

NEVES, A. J.; LEITE, L. P. O desenvolvimento da atenção voluntária no TDAH: ações educativas na perspectiva histórico-cultural. Psicologia Escolar e Educacional, Maringá, v.17, n.1, 2013. Disponível em: <http://www.scielo.br/scielo.php?script=sci_arttext\&pid=S141385572013000100020\&lng=en\&nrm=iso > . Acesso em: 10 jan. 2014.

PACHECO, J. A. Currículo: entre teorias e métodos. Cadernos de Pesquisa, São Paulo, v.39, n.137, p.383-400, 2009. Disponível em: <http://dx.doi.org/10.1590/S010015742009000200004>. Acesso em: 19 nov. 2012.

PERRENOUD, P. A pedagogia na escola das diferenças: fragmentos de uma sociologia do fracasso. Porto Alegre: Artmed, 2001.

RUBLESCKI, A. F. A caminho da escola...: um estudo sobre a educação integrada de crianças com autismo e psicose infantil. 250f. 2004. Dissertação (Mestrado) - Programa de PósGraduação em Educação, Universidade Federal do Rio Grande do Sul, Porto Alegre, 2004.

SANTO, M.; COELHO, A. Necessidades educativas especiais de caráter permanente/prolongado no contexto da escola inclusiva. Trabalho (Disciplina Necessidades Educacionais Especiais de Carácter Permanente/Prolongado no contexto da Escola Inclusiva) - Centro de Formação Contínua de Professores de Ourique, Castro Verde, Aljustrel e Almodóvar, 2006. Disponível em: < http://cenfocal.drealentejo.pt >. Acesso em: 20 out. 2012.

SANTOS, L. L. Currículo em tempos difíceis. Educação em Revista, Belo Horizonte, n.45, p.291-306, 2007.

SAVIANI, D. Escola e democracia - I: a teoria da curvatura da vara. In: SAVIANI, D. Escola e democracia. São Paulo: Autores Associados, 1983. p.40-61.

SERRA, D. C. G. A inclusão de uma criança com autismo na escola regular: desafios e processos. $250 \mathrm{f}$. 2004. Dissertação (Mestrado) - Programa de Pós-Graduação em Educação, Universidade do Estado do Rio de Janeiro, Rio de Janeiro, 2004.

SIQUEIRA, H. S. G.; PEREIRA, M. A. O sentido da autonomia no processo de globalização. Educação, Santa Maria, v.22, n.2, p.12, 1998.

THOMAZI, Á. R. G.; ASINELLI, T. M. T. Prática docente: considerações sobre o planejamento das atividades pedagógicas. Educar, Curitiba, n.35, p.181-195, 2009.

TRAVERSINI, C. S. et al. Processos de inclusão e docência compartilhada no III ciclo. Educ. rev., Belo Horizonte, v.28, n.2, p.285-308, 2012.

VIANNA, C. P.; CARVALHO, M. P.; SCHILLING, F. I.; MOREIRA, M. F. S. Gênero, sexualidade e educação formal no Brasil: uma análise preliminar da produção acadêmica entre 1990 e 2006. Educação \& Sociedade, Campinas, v.32, n.115, p.525-545, jun. 2011. Disponível em: <http://www.scielo.br>. Acesso em: 19 dez. 2012.

ZANATA, E. M. Práticas pedagógicas inclusivas para alunos surdos numa perspectiva colaborativa. 201f. 2004. Tese (Doutorado) - Programa de Pós-Graduação em Educação Especial, Centro de Educação e Ciências Humanas, Universidade Federal de São Carlos, São Carlos, 2004. 
Recebido: 30/08/2013

Aprovado: 18/03/2014

Contato:

Universidade Estadual Paulista

Departamento de Educação e do Programa de Pós-Graduação em

Psicologia do Desenvolvimento e Aprendizagem. Av. Eng. Luiz Edmundo Carrijo Coube, 14-01 Vila Geisel

Bauru | SP | Brasil

CEP 17.033-360 